\title{
O CONSTITUCIONALISMO E A MUDANÇA DOS PRINCÍPIOS NORTEADORES DAS CONSTITUIÇÕES ATÉ A CARTA BRASILEIRA DE 1988
}

\author{
Cleidson Teixeira Vinhas ${ }^{1}$ \\ Rodrigo Corrêa Sosa ${ }^{2}$ \\ Clóvis Dilli ${ }^{3}$ \\ Gustavo Leite da Silva ${ }^{4}$ \\ Alef Saizer Fiori ${ }^{5}$ \\ Marcio Orelio Santos da Silva ${ }^{6}$
}

RESUMO: Este trabalho visou à elaboração de uma linha temporal do constitucionalismo dividido entre antigo e moderno - que teve origem no antigo povo hebreu; também teve passagem pela Inglaterra (Magna Carta de 1215); pela revolução Americana e Francesa; acompanhou a revolução industrial e se estendeu até os dias atuais. Nesse sentido, reunida a contextualização entre linha do tempo e os fatos políticos da sociedade de cada período, a pesquisa teve interesse na evolução do pensamento dos povos até chegar ao Estado Democrático de Direito, aos direitos humanos e ao princípio norteador de todo ordenamento jurídico brasileiro, o princípio da dignidade da pessoa humana. Este trabalho se utilizou de pesquisas anteriores e as obras José Joaquim Gomes Canotilho foram mais de uma vez referenciadas para trazer à baila o conceito ideal de constituição e o entendimento do autor sobre o constitucionalismo. Nesse sentido, além de pesquisas de outros autores, julgados do Supremo Tribunal Federal também complementaram este trabalho (referente aos princípios fundamentais), assim como o próprio texto constitucional de 1988, para comparar o pensamento atual com o dos séculos passados. Os indivíduos experimentaram as distorções e lacunas estruturais deixadas pelo Estado, por esse motivo o poder estatal foi constantemente exigido e obrigado a se reinventar para alcançar um novo patamar que atendesse as novas demandas da sociedade. Em um primeiro momento o mundo clamou por liberdade, por não intervenção estatal, livre comércio e pelo individualismo de Adam Smith (Estado Liberal). Por segundo, a sociedade exigiu a expansão do Estado para que ele pudesse regulamentar as relações dos indivíduos e ofertar prestações positivas à classe trabalhadora que surgira. O Estado Social trouxe o positivismo, o princípio da igualdade, os direitos sociais e os ideais socialistas. Por fim, a ordem mundial experimentou a Segunda Guerra a qual ensinou ao homem que direito e ética jamais podem ser apartados (pós-positivismo), que ao Estado não basta prometer uma vida digna ao cidadão, é dever do governo proporcionar medidas que levem à concretização dos direitos (efetividade). O princípio da dignidade da pessoa humana e os direitos humanos pulsam no coração da Constituição Federal, assim como os ideais democráticos da partição do cidadão nas políticas públicas (Estado Democrático de Direito).

Palavras-chave: Constitucionalismo. Constituição. Dignidade da Pessoa Humana. Estado.

\footnotetext{
${ }^{1}$ Graduação em Administração de Empresas - UFPEL.

${ }^{2}$ Graduação em Tecnologias de processos Gerenciais pelo Centro Universitário - UNINTER.

${ }^{3}$ Pós- Graduação em Gestão de Sistemas Prisionais pela Faculdade Instituto Brasil de Ensino - IBRA (FAMEV). PósGraduação em Segurança Pública pela Faculdade Instituto Brasil de Ensino- IBRA (FAMEV). Graduação em Tecnologias de processos Gerenciais pelo Centro Universitário - UNINTER.

${ }^{4}$ Graduação e mestrado em Meteorologia pela Universidade Federal de Pelotas - UFPel. Licenciatura em Ciências Sociais com Ênfase em Sociologia.

5 Pós- graduado em Gestão de Sistema Prisional. Faculdade Ibra. Licenciatura em Educação Física-MANHANGUERA.

${ }^{6}$ Pós- graduação Lato Sensu em Direito Penal e Processual Penal - FAVENI. Graduação em Licenciatura em História FAVENI. Graduação em Tecnologia dos Recursos Humanos - ANHANGUERA. Graduação em tecnologia em Gestão Pública - ANHGUERA. Pós- graduação lato sensu em Gestão Prisional - FAVENI. Pós- graduação Lato Sensu em Segurança Pública -São Braz.
} 


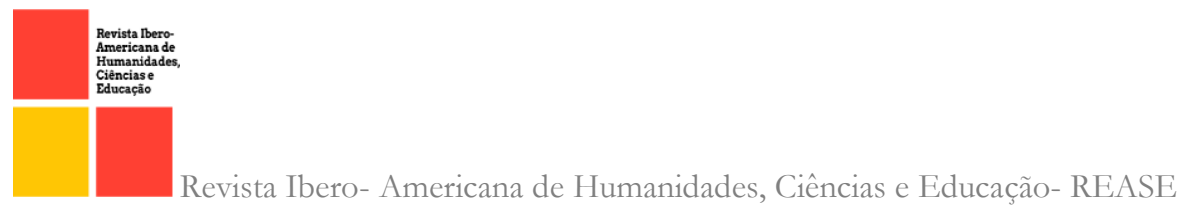

ABSTRACT: This work aimed to prepare a timeline of constitutionalism (divided between ancient and modern) - which originated in the ancient Hebrew people; also passed through England (Magna Charta Libertatum 1215); for the American and French revolution; followed the industrial revolution and extended to the present day. In this sense, together with the contextualization between the timeline and the political facts of society in each period, a research was interested in the evolution of peoples' thinking until reaching the Democratic Rule of Law, human rights and the guiding principle of the entire Brazilian legal system, the principle of human dignity. This work uses previous research and the works José Joaquim Gomes Canotilho were more than once referenced to bring up the ideal concept of constitution and the author's understanding of constitutionalism. In this sense, in addition to research by other authors, judgments by the Federal Supreme Court also complemented this work (referring to fundamental principles), as well as the 1988 constitutional text itself, to compare current thinking with that of past centuries. Individuals experienced the distortions and structural gaps left by the State, for this reason the State power was constantly demanded and forced to reinvent itself to reach a new level that would meet the new demands of society. At first, the world called for freedom, non-state intervention, free trade and the individualism of Adam Smith (Liberal State). Second, society demanded the expansion of the State so that it could regulate the relationships of individuals and offer positive benefits to the emerging working class. The welfare state brought positivism, the principle of equality, social rights and socialist ideals. Finally, the world order experienced the Second War which taught man that law and ethics can never be separated (post-positivism), that the State is not enough to promise a dignified life to the citizen, it is the government's duty to provide measures that lead to realization of rights (effectiveness). The principle of human dignity and human rights are at the heart of the Federal Constitution, as well as the democratic ideals of citizen partition in public policies (Democratic Rule of Law).

Keywords: Constitutionalism. Constitution. Dignity of human person. State.

\section{INTRODUÇÃO}

Esta pesquisa versa a respeito do Constitucionalismo - que é considerado um movimento ideológico-político o qual promoveu profundas mudanças na estruturação dos Estados através da concretização de um documento jurídico conhecido como Constituição. A elaboração de uma Constituição está intimamente ligada à história dos direitos humanos e trata-se do momento mais importante de uma nação, o qual se espera que o legislador constituinte transmita ao solene documento todos os anseios políticos e ideológicos derivados da sociedade de um país.

Ao conhecer a história do constitucionalismo mundial e as principais Constituições que tentaram refletir o pensamento do seu povo, torna-se possível a compreensão da evolução dos princípios basilares que norteavam a elaboração das essenciais Cartas transformadoras até chegar à brasileira Constituição Federal de 1988. Estudar as ideologias das sociedades do passado através da promulgação de suas Cartas possibilitou entender como o Brasil e o mundo chegou ao entendimento dos direitos fundamentais e, em especial, ao princípio da dignidade da pessoa humana.

Atualmente, vigora no Brasil a ordem republicana e democrática e o cidadão é visto 


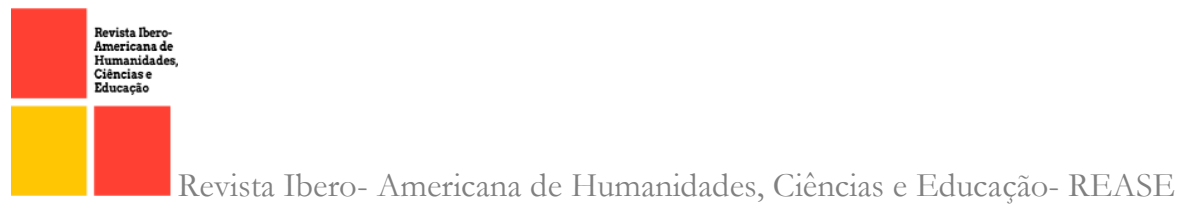

como referencial. Contudo, até chegar ao paradigma atual, o que teria o Estado experimentado a ponto de tornar a pessoa o centro do pensamento da sociedade moderna e focar seus esforços para que o cidadão tenha condições de uma vida digna - e que essa ideologia não seja apenas uma mera promessa de longo prazo, mas sim efetivamente concretizada e proporcionada pelo próprio Estado?

Diante deste problema de pesquisa, este trabalho visou à elaboração de uma linha temporal do constitucionalismo (dividido entre antigo e moderno) - que teve origem no antigo povo hebreu; também teve passagem pela Inglaterra (Magna Carta de 1215); pela revolução Americana e Francesa; acompanhou a revolução industrial e se estendeu até os dias atuais. Nesse sentido, reunida a contextualização entre linha do tempo e os fatos políticos da sociedade de cada período, a pesquisa teve interesse na evolução do pensamento dos povos até chegar ao Estado Democrático de Direito, aos direitos humanos e ao princípio norteador de todo ordenamento jurídico brasileiro, o princípio da dignidade da pessoa humana.

Este documento se utilizou de pesquisas anteriores para formação do embasamento pretendido. Cabe salientar que as obras José Joaquim Gomes Canotilho foram mais de uma vez referenciadas para trazer à baila o conceito ideal de constituição e o entendimento do autor sobre o constitucionalismo. Nesse sentido, além de pesquisas de outros autores, julgados do Supremo Tribunal Federal também complementaram este trabalho (referente aos princípios fundamentais), assim como o próprio texto constitucional de 1988, para comparar o pensamento atual com o dos séculos passados.

\section{DESENVOLVIMENTO}

Em um cenário contemporâneo, entende-se por Constituição o documento criado pela vontade soberana do povo que representa a lei fundamental e suprema de um Estado. Segundo Moraes - hoje ministro do Supremo Tribunal Federal -, é a Constituição que determina a organização estatal (político-jurídica) dispondo sobre a forma do Estado, seus órgãos e suas competências, e, por fim, a aquisição e o exercício do poder (2010, p. 17). É ela - a Carta Magna - a responsável por limitar o poder do Estado e enumerar os direitos e garantias fundamentais. Basicamente uma Constituição ideal de caráter liberal deve ser escrita; conter um sistema de liberdades negativas (direitos fundamentais individuais); reconhecer o princípio da separação dos poderes e o definir; e deve adotar o sistema 
democrático (CANOTILHO, 200o). Todavia, até chegar a este sintético conceito, as Constituições tiveram que sofrer mutações no percurso da história que estão intrinsicamente relacionadas com a evolução do Estado. Este ciclo evolutivo social é explicado pelo Constitucionalismo.

Constitucionalismo é o movimento político-social que tem o objetivo de limitar o poder do Estado sobre o particular (povo, cidadão, particular, contribuinte) e esta limitação estatal está relacionada intrinsecamente à concepção de uma Constituição - levando em consideração o conceito de constitucionalismo moderno (CANOTILHO, 200o). Entretanto, o constitucionalismo antigo - que teve sua origem no seio do povo hebreu e se organizava politicamente por meio do regime teocrático - era regido pela Lei do Senhor e não adotava necessariamente uma constituição escrita. Profetas e governantes eram limitados pela lei divina. Nesse sentido, verifica-se que na antiguidade as cidades gregas apresentavam um regime em que havia participação ativa e direta dos governados no processo decisório político, convergindo para uma democracia constitucional.

Talvez o marco mais primitivo e relevante da manifestação do constitucionalismo da Idade Média seja o de I215 na Inglaterra, a famosa Magna Carta. O reinado do rei inglês João I (ou João Sem Terra como era conhecido) estava comprometido pelas intensas guerras travadas com a França motivadas pelo domínio de territórios. Para tentar reaver a região do Ducado da Normandia - perdida na Batalha de Bouvines para a França em I2I4 -, João Sem Terra promove um aumento de tributos aos barões ingleses. O relacionamento entre o rei e a Igreja Católica também estava abalado, principalmente depois que João se recusou a reconhecer o Cardeal Stephen Longton como representante do clero na Inglaterra.

Em is de julho de 1215, pressionado, o Rei João Sem Terra assinou a Magna Carta (também conhecida como Artigo dos Barões). O documento previa, principalmente, a limitação do poder de tributar da Coroa, pois a instituição de novos impostos estava vinculada à concordância dos nobres. Além das limitações tributárias, a Carta traz os princípios do processo legal e o da igualdade perante a lei, títulos que mais tarde vieram a ser considerados como direitos humanos. Este cenário de abuso do poder monárquico que levou clero e nobreza a limitar o absolutismo real do século XIII foi muito bem abordado pelo filme Hobin Hood (2010), que também mostra o momento histórico da propositura do pioneiro documento. 
Com 63 cláusulas, a Magna Carta foi redigida a punho e de forma corrida, o conteúdo de maior relevância para o contexto dos direitos humanos - um esboço do que seria hoje o princípio do devido processo legal - está na cláusula de número 39: Nenhum homem livre será preso, aprisionado ou privado de uma propriedade, ou tornado fora-dalei, ou exilado, ou de maneira alguma destruído, nem agiremos contra ele ou mandaremos alguém contra ele, a não ser por julgamento legal dos seus pares, ou pela lei da terra; e na de número 40: "Não venderemos, não recusaremos, nem retardaremos a quem quer que seja a administração da justiça.” (ALBUQUERQUE, 1957, p. I6I). Esta importante passagem marcou o início do Constitucionalismo na Idade Média e, a partir de então, a vontade do rei estaria limitada pelo poder da lei.

Com o fim do feudalismo, o poder começa a acumular-se em um governante convergindo para a formação do Estado Absoluto - que se caracteriza pela concentração de poder nas mãos de um monarca que acredita que a vontade dele é lei. Talvez, a emblemática frase de Luís XIV (“o Estado sou Eu”) seja o maior exemplo do regime absolutista da história, em que o rei tudo pode sem nenhum mecanismo de controle limitador. Nesse sentido, não é difícil associar o surgimento do constitucionalismo às incansáveis tentativas de frear o poder do Estado Absoluto que começaram na Idade Média.

Já na Idade Moderna, começa a decadência do absolutismo monárquico e o fortalecimento da Burguesia. Assinada pelo Rei da Inglaterra Carlos I em 1628, após a morte de seu pai (Rei Jaime I), a Petição de Direitos (Petition of Rights) a ele foi imposta pelo Parlamento com a finalidade de reconhecer direitos e liberdades aos súditos do Rei, de impedir o monarca de optar pela convocação do exército e de criar ou majorar novas taxas sem a aprovação parlamentar, além de prever proteção à prisão ilegal. Após tentar dissolver o Parlamento, o Rei provocou uma guerra civil (Revolução Puritana, I64I a I649) que terminou.

com a decapitação do monarca orquestrada pelo Parlamento. Esse momento da história finda o pensamento em que o Rei seria uma figura celestial e incontestável, marca o fortalecimento da monarquia parlamentar e a ascensão política da burguesia.

Outro momento histórico para o Constitucionalismo Antigo é o da celebração da Declaração de Direitos de 1689 (Bill of Rights), pois o distinto documento acompanhou o surgimento de uma monarquia constitucional através da soberania popular. É o fim do 


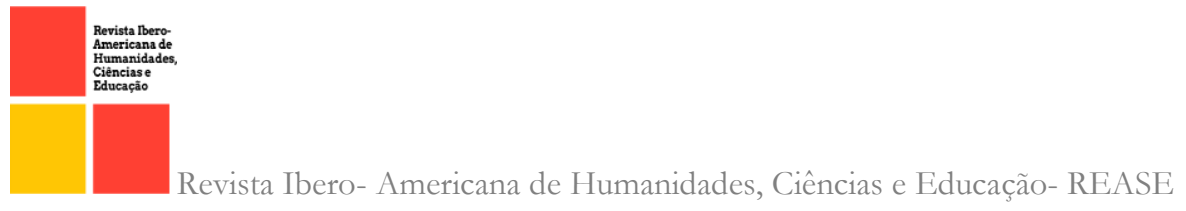

Estado Absoluto na Inglaterra, há o revezamento do poder entre nobres e burgueses. Questões como liberdade de imprensa, da propriedade privada e das liberdades individuais são contempladas na Declaração. A Idade Moderna foi marcada por manifestações históricas do constitucionalismo. A Petition of Rights (1628), a Declaration of Rights do Estado da Virginia (1776), o Habeas Corpus Act (1679), e a Bill of Rights (1689) foram revelações da proteção dos direitos fundamentais da pessoa humana que de modo simplificado tinham o objetivo primeiro de limitar a influência do Estado na esfera privada.

Nesta primeira aparição do constitucionalismo (constitucionalismo antigo), percebe-se que não há a condição de que as Constituições fossem escritas, pois o grande fim era apenas garantir as liberdades dos indivíduos perante o poder estatal. Com o passar do tempo, a relação entre Estado e cidadão começa a exigir mecanismos que garantam ao particular que suas liberdades não serão ceifadas a qualquer momento. Há a necessidade não apenas de palavras, mas de um documento solene e consistente que retrate principalmente a vontade do povo, e de que essa soberania popular seja obrigatoriamente escrita em uma folha de papel - assim se fundamenta o constitucionalismo moderno. Considera-se que todos os documentos citados no período do constitucionalismo antigo foram embriões do constitucionalismo moderno e das constituições escritas (FERREIRA FILHO, 2012, p. 30). Então, após o sucesso da Revolução Francesa, consagra-se a ideia de uma constituição escrita que teve entre seus antecedentes históricos os forais, as cartas de franquia, os pactos e os contratos de colonização.

Efetivamente, o constitucionalismo moderno tem início no século XVIII e é representado pela Constituição dos Estados Unidos (1787) e a Constituição da França (1789). Esses pioneiros documentos emanam um viés liberal intenso (impulsionados pelas ideias dos pensadores dessa época: Adam Smith, Locke e Rousseau), enraizado pelo princípio maior da liberdade que está intrinsicamente associado à proteção da propriedade e aos direitos individuais, exigindo a não interferência do Estado na esfera privada. Neste momento nasce o Estado liberal de direito que considera a Constituição como norma essencial e suprema que

cinge todo o ordenamento jurídico de um país. Esta primeira fase das Constituições escritas traz ideia da supremacia da Constituição, da garantia e proteção dos direitos individuais e da separação dos poderes. 
$\mathrm{O}$ início do século XX é marcado pela crise do Estado Liberal. Agora, o mundo necessitara não somente do absenteísmo estatal e de homens livres e iguais perante a lei pois o liberalismo deixara uma profunda marca de desigualdade social. Era necessária a intervenção estatal na ordem econômica e social para corrigir as falhas sociais provocadas pelo liberalismo, logo a concepção de igualdade social se fortalece em um momento que o princípio da liberdade (base do Estado Liberal) dá lugar ao da igualdade - substitui-se o individualismo pelo interesse público e o bem comum e, assim, nasce o Estado Social ou Estado do Bem-Estar Social. Os novos anseios da sociedade convergiram para que o Estado assumisse uma nova postura e disponibilizasse prestações positivas aos indivíduos, fato que resultou na garantia dos direitos sociais.

A nova postura do Estado foi consolidada pela Constituição do Império Alemão (Constituição de Weimar de 1919), que marcou o auge da crise do Estado Liberal e a origem do Estado Social de Direito. Com a derrota da Tríplice Aliança (Alemanha, ÁustriaHungria e Itália) na Primeira Guerra Mundial, o Império Alemão sofrera uma forte crise econômica que deu lugar à República, influenciada por levantes socialdemocratas e comunistas. Berlim estava tomada por manifestações devido às eleições da Assembleia Constituinte, pois não havia consenso se o Estado deveria ser uma democracia parlamentarista ou socialista (influência pela Revolução Russa). O nome Weimar refere-se à cidade alemã que foi escolhida como sede da Assembleia Constituinte, pois a capital era acometida por uma perigosa instabilidade política. Em II de agosto de 1919 foi promulgada a Constituição de Weimar a qual assegurava a proteção às minorias, a igualdade e a liberdade de expressão e religião, além de elencar um largo rol de direitos fundamentais. Ela ainda augurava o direito à educação e às proteções aos trabalhadores (direitos sociais). Todo esse conteúdo inovador foi um desdobramento da obra de Max Weber, Hans Kelsen, Carl Schmitt e Erich Kauffmann, autores do direito público na época.

No Brasil, na década de 30 , as ideias socialistas se fortalecem e a questão social adquire dimensões desmedidas. A partir da Constituição de 1934, inspirada pela Carta do império alemão, cresce a atividade interventiva do Estado na tentativa que ele gere justiça social, mas deseja-se também que este seja garantidor de liberdades individuais. Ou seja, o paradoxo do estado eficiente e forte, mas que minimamente intervenha. Atendendo as expectativas da época, a nova Carta brasileira não só tentou estabelecer uma nova ordem moderna e liberal, mas também fortalecer o poder estatal e seu papel dirigente no domínio 


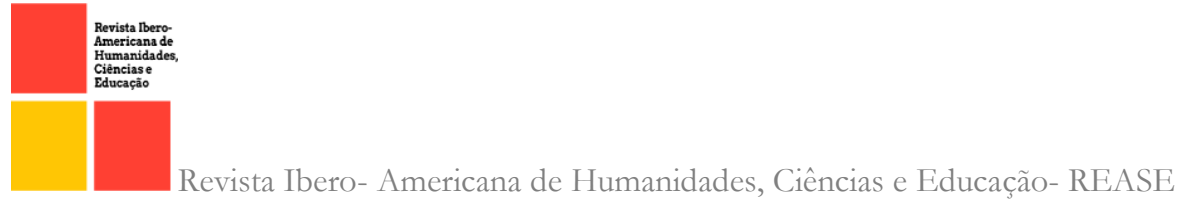

econômico-social.

O Brasil passara da condição de país agrário e exportador, para urbano e industrial; finda a política café com leite e agora as necessidades sociais almejam outros objetivos com o crescimento das cidades. A Carta de 1934 traz à baila diversas inovações até então não previstas em Leis brasileiras anteriores como: as leis trabalhistas, o voto feminino e o voto secreto. Ela reduziu a autonomia dos estados federativos e fortaleceu o poder do governo federal; previa a possibilidade de nacionalizar empresas estrangeiras e outorgar monopólio estatal sobre empresas específicas; cuidou dos direitos culturais e do direito a todos à educação (ênfase na consciência da solidariedade humana); obrigatoriedade e gratuidade do ensino primário e o ensino religioso facultativo. Apesar da sua vida curta - sucedida após a outorga da Carta de 1937, pela ditadura do presidente Getúlio Vargas -, a Constituição Federal de 1934 é considerada até hoje uma das normativas máximas mais inovadoras da história do Brasil.

Ao fazer um comparativo geral entre o Estado liberal e o Estado social, é possível dizer que este tem como meta a concretização efetiva dos direitos individuais (Estado material), enquanto aquele era basicamente um Estado formal, criado para seguir a lei em sua literalidade. O Estado social evoluiu ao patamar assistencialista interventor e, ao mesmo tempo, tornou-se legislador - legislação econômica e social -; através dos serviços públicos também adquiriu a competência de administrador; e por meio das empresas públicas se torna Estado empresário; ou seja, agigantou-se (GOMES e MORAIS, 2004, p. 197).

Após a Segunda Guerra Mundial, surge um novo pensamento que se reflete no conteúdo das Constituições. O princípio da dignidade da pessoa humana é o grande pilar desse novo pensar que nasce devido às barbáries cometidas por regimes totalitários Fascismo e Nazismo -, e é fundamento que dá origem ao neoconstitucionalismo. Espera-se que as novas Cartas tragam opções políticas que obriguem o Estado a prover saúde, educação e reduzir as desigualdades, por exemplo, além de reivindicar valores relacionados à dignidade humana para evitar os erros cometidos no passado. Essas extensas modificações Estatais trazidas pelo neoconstitucionalismo consolidaram o chamado Estado Constitucional de Direito, que por sua vez reconheceu a força normativa da Constituição, a qual exige compatibilidade do ordenamento jurídico com as normas constitucionais (BARROSO, 2005, p. I2.

O período Pós-Segunda Guerra exige que as Constituições incorporem equidade, 
justiça social e moralidade - valores que avizinham direito e ética - garantindo o mínimo existencial para todos os indivíduos (princípio da dignidade da pessoa humana). O póspositivismo é a corrente filosófica que vigorava neste marco temporal (metade do século $\mathrm{XX)}$ e entende que o Direito não se encontra isolado da moral, logo, tanto na criação como na aplicação da lei, deve-se considerá-la. O centro do sistema jurídico passa a ser a Constituição, e sua supremacia e força normativa - que agora incorpora e busca a concretização de valores

- passa a condicionar a validade de todo o Direito. Nesse sentido, a concretização dos direitos fundamentais deve ser realizada na prática, e a proteção deles deve ser exercício de todos os poderes.

Em 1988 nasce a brasileira Constituição Federal que carrega os novos ideais do mundo e apresenta ao povo brasileiro, após anos de regime militar, o Estado Democrático de Direito. A partir de então vigora a Democracia, todo poder emana do povo e o grande princípio basilar desta nova e ilustre Carta é o da dignidade da pessoa humana. O grande prisma é o sujeito humano, logo o Estado passa a ter responsabilidade de ofertar ao cidadão o exercício de uma vida digna - uma vida que garanta o mínimo existencial. Já no artigo primeiro da Constituição Federal, o legislador constituinte informa os fundamentos do Estado Democrático de Direito da República Federativa do Brasil e mostra que a nação brasileira vive não apenas em um Estado Democrático, mas especialmente em um Estado de Direito (LOWENTHAL, 200I, p. 33I). A Constituição Federal de I988 em seu artigo I estabelece:

Art. Io - A República Federativa do Brasil, formada pela união indissolúvel dos Estados e Municípios e do Distrito Federal, constitui-se em Estado Democrático de Direito e tem como fundamentos:

I - a soberania;

II - a cidadania;

III - a dignidade da pessoa humana;

IV - os valores sociais do trabalho e da livre iniciativa; V - o pluralismo político

Parágrafo único - Todo poder emana do povo, que o exerce por meio de representantes eleitos ou diretamente, nos termos dessa Constituição.

O legislador é muito claro ao informar expressamente o rol de princípios fundamentais o qual está fundamentado a república brasileira. Princípio fundamental é o valor escolhido pelo poder constituinte originário na preparação da Constituição, trata-se da escolha política fundamental (CANOTILHO, 1992, p. I09I). No caso da Carta de I988, 

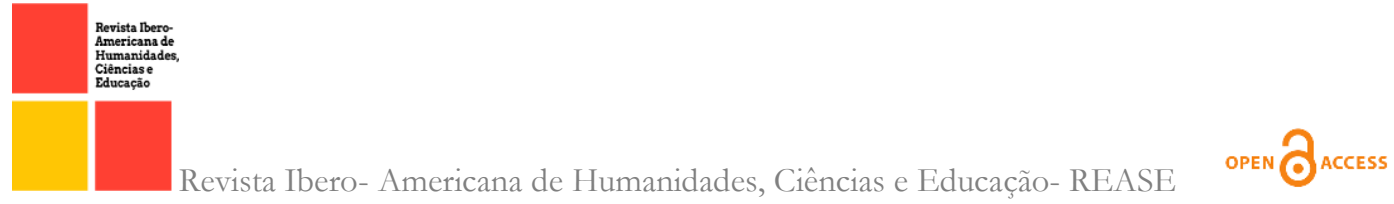

são diversos princípios fundamentais os quais estão dispostos não somente no artigo primeiro, mas se estendem até o quarto artigo (Título I). Nesse sentido, cabe um breve desdobramento do

conteúdo dos incisos do artigo primeiro da Constituição Federal de 1988, para entender melhor a intenção da Assembleia Constituinte e o momento político da época.

Ao trazer a Soberania no primeiro inciso, entende-se que a vontade do legislador não é somente garantir que o Estado não se subordine a outro poder, seja internamente ou no plano internacional, mas, sobretudo, mostrar que este fundamento deve ser observado pela perspectiva democrática, levando em consideração a soberania popular em que todo o poder emana do povo. A Cidadania está atrelada ao conceito de democracia, no sentido de participação do cidadão na vida política do Estado (MORAES, 2oro, p. 6r).

A confirmação maior que o Brasil é um país que adota o sistema capitalista está no inciso quarto o qual enaltece a livre iniciativa e, ao mesmo tempo, demonstra que o trabalho tem valor social. Já o fundamento do pluralismo político aí está para garantir a inclusão dos diferentes grupos sociais no contexto político do país, assim como proporcionar a liberdade das convicções políticas e filosóficas do cidadão.

Por fim, o valor basilar e fonte de todos os direitos fundamentais da Constituição Federal de 1988, o princípio supremo da dignidade da pessoa humana traz o entendimento que o amparo às pessoas deve ser vista como um fim em si mesmo. O próprio Supremo Tribunal Federal (STF) no HC 85.237/2005 afirma que este fundamento é "significativo vetor interpretativo, verdadeiro valor-fonte que conforma e inspira todo o ordenamento constitucional vigente em nosso País e que traduz, de modo expressivo, um dos fundamentos em que se assenta, entre nós, a ordem republicana e democrática consagrada pelo sistema de direito constitucional positivo".

Este valor-fonte carrega uma especial densidade normativa capaz de invalidar quaisquer normas com ele conflitantes (eficácia negativa) e também tem o poder de obrigar o próprio Estado a adotar medidas políticas para sua implementação efetiva. Como exemplo do alcance do princípio da dignidade da pessoa humana em assuntos sensíveis e relevantes para o ordenamento jurídico brasileiro, o STF fez valer o valor-fonte fundamental (combinado com o direito à busca pela felicidade) ao reconhecer legítima a união homoafetiva como entidade familiar. Segundo a Corte: “a extensão, às uniões homoafetivas, do mesmo regime jurídico aplicável à união estável entre pessoas de gênero 
distinto justifica-se e legitima-se pela direta incidência dos princípios constitucionais da igualdade, da liberdade, da dignidade, da segurança jurídica e do postulado constitucional implícito que consagra o direito à busca da felicidade, os quais configuram, numa estrita dimensão que privilegia o sentido de inclusão decorrente da própria Constituição da República (art. Io, III, e art. $3^{\circ}$, IV), fundamentos autônomos e suficientes aptos a conferir suporte legitimador à qualificação das conjugalidades

entre pessoas do mesmo sexo como espécie do gênero entidade familiar.” (ADI №. 4.277/DF, 2011.

\section{CONCLUSÃO}

Ao traçar a linha do tempo do constitucionalismo esta pesquisa deparou-se, de modo intencional, com a evolução histórica dos direitos humanos, mesmo que de modo superficial. As Constituições das nações foram documentos solenes que começaram a carregar os anseios da sociedade e a maneira de como governantes e governados vislumbravam um modelo de Estado. A cada nova Carta, nascera não somente um princípio ou pensamento maior que refletia as ideologias em que as noções estavam embebidas, mas também o alerta para que o fantasma do retrocesso fosse banido das vindouras normas, na intenção de que os erros do passado jamais fossem esquecidos e cometidos novamente - embora muito vezes esse cenário retrógado tenha se concretizado. A eterna guerra por poder entre Estado e governados mostrou-se uma gangorra em que a tendência do equilíbrio pode ser a alternativa menos onerosa.

Entre altos e baixos, a onda evolucionária do pensar na coletividade ou pensar em sociedade chegou ao Brasil através da Constituição de 1988. Esse moderno pensamento que colocou a pessoa/cidadão como objetivo central através da dignidade humana só pode ser alcançado através dos históricos confrontos entre Estado e indivíduo. Os conflitos chaves foram abordados pelo constitucionalismo por intermédio da evolução das cartas máximas e seus princípios fonte, os quais refletiram a principal intenção da sociedade.

Os indivíduos experimentaram as distorções e lacunas deixadas pelo Estado, por esse motivo o poder estatal foi constantemente exigido e obrigado a se reinventar para alcançar um novo patamar que atendesse as novas demandas da sociedade. Em um primeiro momento a ausência de uma Constituição foi contestada (constitucionalismo antigo); por segundo a simples não intervenção do Estado não atendia as demandas da 
nova sociedade (Estado Liberal); depois, o Estado expandido e interventor que não concretizava o direito da coletividade e não associava o direito com a ética foi à pauta (Estado Social); e, por fim, o Estado Democrático de direito que vigora atualmente.

Nesse sentido, cabe salientar que a evolução de um marco para outro do constitucionalismo não exclui o marco ultrapassado, ou seja, não exclui por completo o pensamento anterior. O próprio Estado Democrático de Direito carrega características do Estado Liberal e do Estado Social. A atual Constituição Federal, por exemplo, não somente.

traz em seu conteúdo o princípio da legalidade e da igualdade, como promove a expansão e derivação desses alicerces passados.

\section{REFERÊNCIAS BIBLIOGRÁFICAS}

ALBUQUERQUE, Francisco Uchoa de. Sobre a carta política de João Sem Terra. Revista da Faculdade de Direito, Fortaleza, v.II, 1957, p.153-163.

BARROSO, Luís Roberto. Neoconstitucionalismo e Constitucionalização do Direito: O triunfo tardio do Direito Constitucional no Brasil. In: Revista da Associação dos Juízes Federais do Brasil. Ano 23, n. 82, 2005.

BRASIL. Constituição (1988). Constituição da República Federativa do Brasil. Brasília, DF: Senado Federal: Centro Gráfico, 1988.

BRASIL. Supremo Tribunal Federal. Habeas Corpus №. 85.237. Relator: Ministro Celso de Mello. Julgado em 17 mar. 2005. Publicado no DJ em 29 abr. 2005. Disponível em: 〈www.stf.jus.br >. Acesso em or nov. 202I.

BRASIL. Supremo Tribunal Federal. Acórdão proferido em Ação Direta de Inconstitucionalidade №. 4.277/DF. Órgão Julgador: Tribunal Pleno. Relator: Ministro Ayres Britto. Julgado em o5 mai. 20Ir. Publicado no DJ em I4 out. 20II. Disponível em: $\langle$ www.stf.jus.br $\rangle$. Acesso em or nov. 202I.

CANotilho, J. J. Gomes. Constituição Dirigente e Vinculação do Legislador. Coimbra: Editora Coimbra, 1992.

CANOTILHO, J. J. Gomes. Direito constitucional e teoria da constituição, $4^{\text {a }}$ edição. Coimbra: Almedina, 2000.

FERREIRA FILHO, Manoel Gonçalves. Curso de Direito Constitucional, $38^{\mathrm{a}}$ edição. São Paulo. Ed. Saraiva: 2012, p. 30. 


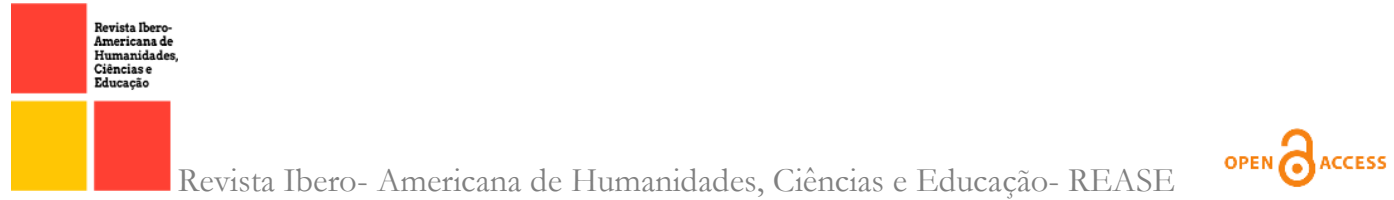

GOMES, A. C. N.; MORAIS, R. J. de. De uma visão jurídico-constitucional a uma proposta pragmático-econômica dos direitos sociais. Belo Horizonte: Fórum, 2004. HOBIN HOOD. Direção: Ridley Scott. Produção de Ridley Scott, Brian Grazer, Russell Crowe. Estados Unidos: Imagine Entertainment; Relativity Media; Scott Free Productions, 2010. I DVD.

LOWENTHAL, A. M. V. Exame da expressão "a dignidade da pessoa humana" sob o ângulo de uma semiótica jurídica. São Paulo: Loyola, 200 .

MORAES, Alexandre de. Constituição do Brasil Interpretada e Legislação Constitucional, $9^{\text {a }}$ edição. São Paulo Editora Atlas: 2010. 